\title{
Editorial
}

\section{A new style for the nineties}

“. . . how the style refines" (Alexander Pope)

Readers who are interested in both the form and the content of the Journal will have noted some changes in this issue that have been introduced both to give it a more modern look and to bring it into line with the restyling that has affected all the house journals published by the British Medical Association. The British Medical Journal, which is to some extent the mother of us all, itself had a face lift some months ago which has given it a crisper look and allowed its layout to be much more flexible. Although the changes were not universally popular at the time they first appeared, most of the critics have been won over and the new appearance has great appeal.

The British Journal of Industrial Medicine has changed little in appearance since it was first published, although it is smaller in size than the first few volumes. The present look dates back to 1977, although the introduction of the Vancouver style of referencing in 1980 brought about some minor alterations. We hope that readers will like our new style and we shall be glad to hear comments, complimentary and adverse, from those who may hold strong views.

Style is not all, however, and ensuring the quality of the content of the journal is still our main objective. The mix of papers published has changed substantially over the years and has, naturally, reflected both the changes that have taken place in occupational health and the inclinations of individual editors. When it first appeared toxicology and clinical reports were frequently published; latterly, the bulk of the papers report the results of epidemiological studies and case reports are uncommon. Toxicology is beginning to assume greater prominence after a period in the doldrums, both because this editor has a special interest in it and because new legislation in the United Kingdom has dictated that it occupies a greater place in the thinking of occupational physicians and in the curriculum of their examinations than it might have done in the recent past.

The BJIM welcomes contributions on all aspects of occupational health and is glad to consider papers in the wider context of environmental health; indeed, it seems unwise to consider occupational health as anything but a subset of environmental health since to assume that people are different away from work than they are at work is illogical and the effects that the two milieux may have on health cannot properly be considered separately one from another.

We publish both main papers and short reports and we welcome suggestions for editorials; we particularly welcome correspondence either on matters arising from published papers or on other matters that do not warrant a more formal presentation. The correspondence column has been slow to pick up, probably because issues cannot be dealt with with the immediacy of a weekly journal; however, we would like to encourage readers to submit letters since a lively correspondence column adds greatly to the enjoyment of a journal.

We would also like contributors to submit fillers to be used when there are gaps at the end of papers that would otherwise be left blank. These should be no more than 500 words in length and generally shorter. If any illustrative material is included the number of words should be reduced accordingly. Fillers may take as their subject matter almost anything that could be thought to be of interest to those who read the journal; clinical, historical, personal, or anecdotal accounts are all acceptable so long as they are well written and interesting.

On a more general theme; it is clear that by no means all those who contribute to the journal read the instructions to authors which we dutifully print each month on the inside cover and in more detail in January. I would like to emphasise a few of the more salient points in the hope that they may be read in an editorial if not in any other form.

Brevity and clarity are the greatest possible virtues that an editor can hope to find in a manuscript (I assume in all this that the scientific content is adequate); when you finish a paper think of ways in which you can reduce its bulk by a third and go on doing this until there is not a spare word anywhere. The introduction to a paper should be a short and simple statement of how you came to set about the piece of work that you are describing. There is little virtue in making it a mini review other than to show that you have taken the trouble to carry out a 
computer search. Do not repeat material that forms part of the introduction in the discussion which itself should not be a reiteration of all that is known about the subject in hand but should be used to describe the importance of your observations and how they agree or disagree with what others have found. If they disagree then some possible reasons to account for this are in order.

Epidemiological studies generally benefit from some pondering on the extent to which their results are valid and likely to be generally applicable but, again, not at too great a length.

The methods used in a study should be described in such a way as to allow the reader a clear understanding of how the study was carried out but only if new methods are used should these be described in detail with the aim of allowing others to repeat them.

When giving the results of a study, few authors seem able to resist the temptation to over analyse; once more the computer has a lot to answer for. When it took several hours, if not days, to perform an analysis of variance or a multiple regression by hand most people found no difficulty in using these techniques only when there was a good reason to do so. Now that software packages may be bought for a few pounds, anyone can do the most complicated statistical analysis on a "let's do it and see" basis. This has tended to lead to an atrophy of the critical faculties and to an epidemic of statisticus multiplex.

No over analysis then, and certainly no over referencing. I urge authors to limit themselves to no more than two references per page of type text; the impression that many editors have is that the length of an author's reference list is designed more to impress than to inform. And when, as one knows only too well, many of the references are incorrect because they have not been checked-much less read in some cases-then their inclusion has little to commend it. When your short list of references is prepared, do please see that it conforms with the Vancouver style; we do not undertake to change or check references in the editorial office and if they do not conform to our requirements you will get the manuscript back and this will delay publication. Using an incorrect style of referencing also raises the nasty thought in the editor's mind that the paper has been rejected by another journal.

The authors of this journal do not seem often to engage in some of the malpractices that have been described elsewhere, especially by the Editor of the $B M J .{ }^{1}$ Nevertheless, authors do occasionally submit a paper to us that they have submitted to another journal or that has been published in whole or in part elsewhere. It is often difficult to detect instances of this type of deceit but when it is detected those concerned can be confident that any future offerings will not be looked on with very great favour.

HA WALDRON

Editor

1 Lock S. A difficult balance. Editorial peer review in medicine. London: Nuffield Provincial Hospitals Trust, 1985.

\section{Guidance for authors}

The British Journal of Industrial Medicine publishes material that is relevant to any aspect of occupational health. Papers that deal with environmental medicine will also be considered. The journal publishes four types of communication, original papers, short reports (which may include reports of clinical material), editorials, and letters to the Editor. Review articles are normally specially commissioned, and authors should not submit such a review without prior consultation with the Editor.

All material submitted to the journal must be typewritten on one side of the paper only with double spacing and wide margins. Manuscripts must be submitted in triplicate to the Editor, British Journal of Industrial Medicine, BMA House, Tavistock Square, London WC1H 9JR; they must conform with the recommendations given below. Manuscripts must be written in English and spelling must follow the conventions in the Chambers Twentieth Century Dictionary. Both SI units and their equivalents must be given throughout. Authors should note that clarity and brevity are virtues that are given great weight when considering a paper for publication. The Editor cannot enter into correspondence about papers that are rejected as being unsuitable for publication and his decision is final. Rejected manuscripts will not be returned to authors, instead they will be kept securely for three months and then shredded. Authors are advised, therefore, not to submit original illustrations with their manuscripts but rather good quality reproductions. The original illustrations should be forwarded to the Editor on acceptance of the manuscript.

Papers are accepted on the understanding that the work described has not appeared in whole elsewhere and that they are subject to editorial revision. Where the findings have been published elsewhere in part this must be clearly stated and the submitted manuscript should be accompanied by a copy of the publication that contains those findings. If part of the findings are contained in a manuscript that is under consideration elsewhere a copy of that manuscript should be included with that submitted to the journal. A letter giving consent to publication must be signed by all those whose name appears on the manuscript. Papers that describe studies carried out on human subjects must give evidence that the protocol was approved by an ethical committee and that all the subjects gave their informed consent.

There is no prescribed length for original papers but authors should not submit papers which exceed 10000 words (about 30 typewritten sheets) without first consulting the Editor.

Original papers should follow the requirements of the International Steering Committee of Medical Editors; details, with which authors should familiarise themselves, are to be found in the British Medical Journal (1979;i:532-5). Papers should be prefaced by an abstract of the argument and findings and should be more comprehensive than a summary. The ab- 